\title{
Monozygotic dichorionic-diamniotic pregnancies following single frozen-thawed blastocyst transfer: a retrospective case series
}

He Li $i^{*+}\left(\mathbb{D}\right.$, Tingting Shen ${ }^{1+}$ and Xiaoxi Sun ${ }^{1,2}$

\begin{abstract}
Background: The primary aim of the study is to report cases of monozygotic dichorionic-diamniotic (DC-DA) pregnancies after single frozen-thawed blastocyst transfer.

Methods: This is a retrospective case series. All single frozen-thawed blastocyst transfer cycles performed between June 2013 and December 2018 at the Shanghai Ji Ai Genetics and IVF Institute, Obstetrics and Gynecology Hospital, Fudan University, Shanghai, China, were reviewed retrospectively. We included frozen embryo transfer (FET) cycles which clinical pregnancy was confirmed with multiple gestational sacs showed on ultrasonography at around 6 to 7 weeks of gestation. We then conducted an in-depth analysis to further exclude cases which contained newborns of different genders or natural FET cycles.

Results: Five thousand four hundred fifteen frozen-thawed single blastocyst transfer cycles were preformed between June 2013 and December 2018 at the Shanghai Ji Ai Genetics and IVF Institute, Obstetrics and Gynecology Hospital, Fudan University, Shanghai, China. Of these, fourteen women underwent a single blastocyst transfer and then achieved clinical pregnancy with an ultrasound diagnosis of multi-chorionic pregnancy. With one natural cycle FET excluded, we finally included thirteen single blastocyst transfer cycles performed in downregulated controlled FET or hormone replacement FET, in which the possibility of concurrently spontaneous pregnancy was extremely small. These included 13 cases reveal the phenomenon of monozygotic DC-DA twinning after single blastocyst transfer, which challenges the classical theory that only monochorionic pregnancy could happen after 3 days of fertilization.
\end{abstract}

Conclusion: This case series suggest that single blastocyst transfer could result DC-DA pregnancies during IVF treatment.

Keywords: Assisted reproductive technology, Monozygotic dichorionic-diamniotic twinning, Single blastocyst transfer

\footnotetext{
*Correspondence: lihe198900@163.com

He Li and Tingting Shen should be regarded as joint First Authors.

${ }^{1}$ Shanghai Ji Ai Genetics and IVF Institute, Obstetrics and Gynecology Hospital, Fudan University, Shanghai 200011, China

Full list of author information is available at the end of the article
}

(c) The Author(s). 2020 Open Access This article is licensed under a Creative Commons Attribution 4.0 International License, which permits use, sharing, adaptation, distribution and reproduction in any medium or format, as long as you give appropriate credit to the original author(s) and the source, provide a link to the Creative Commons licence, and indicate if changes were made. The images or other third party material in this article are included in the article's Creative Commons. licence, unless indicated otherwise in a credit line to the material. If material is not included in the article's Creative Commons licence and your intended use is not permitted by statutory regulation or exceeds the permitted use, you will need to obtain permission directly from the copyright holder. To view a copy of this licence, visit http://creativecommons.org/licenses/by/4.0/ The Creative Commons Public Domain Dedication waiver (http://creativecommons.org/publicdomain/zero/1.0/) applies to the data made available in this article, unless otherwise stated in a credit line to the data. 


\section{Background}

When a single embryo divides into two after fertilization defines the type of twin pregnancy. There is a classical theory presented by Corner about the timing of embryo division and twin pregnancy development: within 3 days of fertilization, dichorionic-diamniotic (DC-DA) twins; between 4 and 8 days, monochorionic-diamniotic (MCDA) twins; and between 9 and 12 days, monochorionicmonoamniotic (MC-MA) twins; and rarely, after 12 days, conjoined twins [1, 2].

Assisted reproductive technology (ART) has been associated with multiple gestations as a result of transfer with more than one embryos, which may develop into DC-DA twins. However, the frequency of monozygotic twinning after ART also increases, which varies from 0 to $13.2 \%$ compared with $0.4 \%$ of live births in spontaneous conception population [3, 4]. Although the specific mechanism of the increased risk of monozygotic twinning with in vitro fertilization (IVF) is controversial, researchers have proposed a lot of risk factors including extended embryo culture, female age and certain IVF procedures, especially those related to micromanipulation of the zona pellucida as intracytoplasmic sperm injection (ICSI) or assisted hatching (AH), embryo biopsy and embryo cryopreservation [3-8].

The information on monozygotic DC-DA twinning after single blastocyst transfer is extremely limited. As it differs with the deep-rooted multiple pregnancy theory that single blastocyst transfer should only lead to MCDA or MC-MA twinning, more studies and further investigation are needed. Many DC-DA twinning are suspected to be the results of either transfer of more than one embryo or less common, spontaneous pregnancies at the same time [9]. DC-DA monozygotic twinning rate is underestimated because genetic testing of offspring is rarely performed [10]. Therefore, we collected and analyzed data of thirteen cases of monozygotic DC-DA twinning after single blastocyst transfer in downregulated or hormone replacement frozen embryo transfer (FET) cycles.

\section{Material and methods}

We retrospectively reviewed all frozen thawed single blastocyst transfer cycles performed between Jan 2013 and December 2018 at the Shanghai JiAi Genetics \& IVF Institute. This study was approved by the Ethics Committee of Assisted Reproductive Medicine in Shanghai JiAi Genetics \& IVF Institute (JIAI E2020-02).

FET cycles were analyzed when clinical pregnancy was confirmed alone with one or more gestational sacs showed on ultrasonography at around 6 to 7 weeks of gestation. We further identified all patients with two or more gestational sacs noted on initial ultrasound, suggesting possible multi-chorionic monozygotic pregnancies. We then conducted an in-depth analysis to further exclude cases which contained newborns of different sexes or natural FET cycles, in order to rule out the possibility of dizygosity. Demographic data and IVF treatment information including obstetrical and neonatal outcome data of the included cases were summarized and analyzed. Moreover, we compared the demographic and IVF-FET cycle characteristics between monochorionic and dichorionic twining group. Comparison of quantitative variables were performed using Student's t-test, while categorical variables were compared using a $x^{2}$ analysis. All statistical analyses of the data were performed using the SPSS program V.21.0 (SPSS), and a $P$ value $<0.05$ was considered statistically significant.

Women underwent IVF, ICSI or preimplantation genetic testing (PGT) treatment in the center according to clinical indications. Protocols of controlled ovarian stimulation included: gonadotropin-releasing hormone $(\mathrm{GnRH})$ antagonist protocol, short or long GnRH agonist protocol, and clomiphene citrate (CC) + human menopausal gonadotropin (hMG) or follicle-stimulating hormone (FSH) protocol.

Oocyte retrieval was performed 34-36 h after human chorionic gonadotropin (hCG) or GnRH agonist trigger under transvaginal ultrasound guidance. Obtained oocytes were fertilized using either conventional IVF or ICSI as clinically indicated, and incubated in fertilization media (Vitrolife, Sweden). Fertilization was judged by the appearance of two pronuclei and a second polar body at $16-18 \mathrm{~h}$ after IVF or ICSI. Fertilized zygotes were grown to the blastocyst stage in sequential culture media (G1 and G2, Vitrolife).

Assisted hatching was performed on D3 embryo with an $18 \mu \mathrm{m}$ hole made in the zona pellucida of the embryos. PGT biopsy was performed on day 5 or day 6 embryo. Approximately 3-5 trophectoderm cells were biopsied using a pipette and placed into polymerase chain reaction (PCR) tubes. Then the cells were either directly used for Whole genome amplification (WGA) or cryopreservation for later WGA. All the testing experiments and data analysis were completed in Ji Ai local genetic laboratory.

Endometrial preparation for FET was achieved by either hormone replacement treatment (HRT) or downregulated HRT-FET. For HRT-FET, on day 3 of the menstrual cycle, estradiol valerate (E2, Progynova, Schering AG, Berlin, Germany) was commenced $4 \mathrm{mg}$ daily for 10-12 days. When the thickness of the endometrium reaches at least $7 \mathrm{~mm}$ on pelvic ultrasound scanning, progesterone in oil $(80 \mathrm{mg})$ was added. Ultrasound was performed not only to evaluate endometrial lining, but also to confirm no dominant follicles in bilateral ovaries. For down-regulated FET, GnRH agonist was usually given in the mid luteal phase (day 21) of the menstrual 
cycle. Pituitary down-regulation was confirmed on the second or third day of the expected next menstruation. If baseline levels have been reached and the ovaries are quiescent on pelvic scanning, HRT with estradiol valerate was started as described above.

Blastocyst transfer was scheduled on the sixth day of starting intramuscular progesterone. Single blastocyst with the best morphology was transferred under transabdominal ultrasound guidance using a soft catheter. After thawing, embryo score was assessed according to Gardner morphological criteria [11], on the basis of the degree of expansion and the development of the inner cell mass and trophectoderm. Serum hCG level was checked 14 days after FET. All hormone therapy was stopped if the serum hCG level was negative. Pregnant women continued the hormonal therapy until 12 weeks of gestation.

\section{Results}

Five thousand four hundred fifteen single blastocyst FET cycles were performed between June 2013 and December 2018 at our infertility center and 2510 (46.4\%) resulted in a clinical pregnancy. From the 1510 clinical pregnancies, $43(2.8 \%)$ were monozygotic twinning (MZT) pregnancies. 14 (0.9\%) of total pregnancies were monozygotic DC-DA pregnancies which had two gestational sacs on 6-7 gestational weeks' ultrasound examination. $29(1.9 \%)$ of total clinical pregnancies were monozygotic monochorionic pregnancies. Excluding one natural cycle FET, finally we included 13 women who were in down-regulated controlled FET or hormone replacement therapy FET (with FET cycle ultrasound documenting absence of spontaneous ovulation), in which concomitant spontaneous pregnancy could not happen. The incidence rate of monozygotic DC-DA pregnancies was $0.5 \%$ (13/2510) after single blastocyst FET.

Demographic data about these 13 patients are showed in Table 1. ART treatment information are showed in Table 2. Pregnancy outcomes are showed in Table 3. Demographic and IVF-FET cycle characteristics between monochorionic and dichorionic twining group were comparable, which was showed in Table 4. All the included thirteen patients had at least one reported risk factors associated with monozygotic twinning, including the procedure of ICSI $(9 / 13)$, assisted hatching (5/13), and blastocyst transfer (13/13). PGT was performed in $5 / 13$ patients. Figure 1 shows the initial ultrasound confirming dichorionic-diamniotic twinning at 6 to 7 weeks of gestation.

\section{Discussion}

Since the first case of monozygotic twinning associated with IVF was reported in 1984 [12], the incidence of MZT following assisted reproduction has been continually rising [13]. The development model of monozygotic twinning was described by Corner for the first time in 1955 and has become accepted as golden rule, which is now often published in textbooks and literature. A

Table 1 Demographic characteristics

\begin{tabular}{|c|c|c|c|c|c|c|c|c|c|}
\hline & $\begin{array}{l}\text { Age } \\
\text { (years) }\end{array}$ & $\begin{array}{l}\text { BMI } \\
(\mathrm{kg} / \mathrm{m} 2)\end{array}$ & Gravidity & Parity & Diagnosis & $\begin{array}{l}\text { Antral } \\
\text { follicle } \\
\text { count }\end{array}$ & $\begin{array}{l}\text { No. of prior } \\
\text { IVF attempts }\end{array}$ & $\begin{array}{l}\text { No. of prior D3 } \\
\text { embryos } \\
\text { transferred }\end{array}$ & $\begin{array}{l}\text { No. of prior } \\
\text { blastocysts } \\
\text { transferred }\end{array}$ \\
\hline Case 1 & 31 & 21.23 & 4 & 0 & $\begin{array}{l}\text { Recurrent miscarriage, } \\
\text { male reciprocal } \\
\text { translocation }\end{array}$ & 27 & 0 & 0 & 0 \\
\hline Case 2 & 38 & 24.97 & 1 & 0 & $\begin{array}{l}\text { Tubal factor and male } \\
\text { factor }\end{array}$ & 13 & 2 & 2 & 0 \\
\hline Case 3 & 33 & 17.97 & 2 & 0 & Tubal factor & 24 & 0 & 0 & 0 \\
\hline Case 4 & 34 & 17.19 & 0 & 0 & Male factor & 18 & 0 & 0 & 1 \\
\hline Case 5 & 41 & 21.26 & 3 & 1 & $\begin{array}{l}\text { Tubal factor and male } \\
\text { factor }\end{array}$ & 13 & 0 & 0 & 0 \\
\hline Case 6 & 33 & 19.92 & 1 & 1 & PCOS and male factor & 19 & 0 & 4 & 0 \\
\hline Case 7 & 28 & 20.51 & 0 & 0 & Endometriosis & 8 & 0 & 0 & 0 \\
\hline Case 8 & 39 & 23.31 & 3 & 0 & Recurrent miscarriage & 18 & 0 & 0 & 1 \\
\hline Case 9 & 38 & 19.92 & 3 & 0 & SNM1 mutation & 24 & 0 & 0 & 3 \\
\hline Case 10 & 30 & 18.59 & 0 & 0 & $\begin{array}{l}\text { Male robertsonian } \\
\text { translocation }\end{array}$ & 16 & 0 & 0 & 0 \\
\hline Case 11 & 42 & 22.83 & 2 & 1 & Unexplained infertility & 12 & 0 & 0 & 0 \\
\hline Case 12 & 43 & 21.97 & 2 & 0 & Recurrent miscarriage & 8 & 0 & 0 & 1 \\
\hline Case 13 & 32 & 25.39 & 2 & 1 & Tubal factor & 29 & 0 & 0 & 0 \\
\hline
\end{tabular}

PCOS polycystic ovarian syndrome, SNM1 survival motor neuron gene 


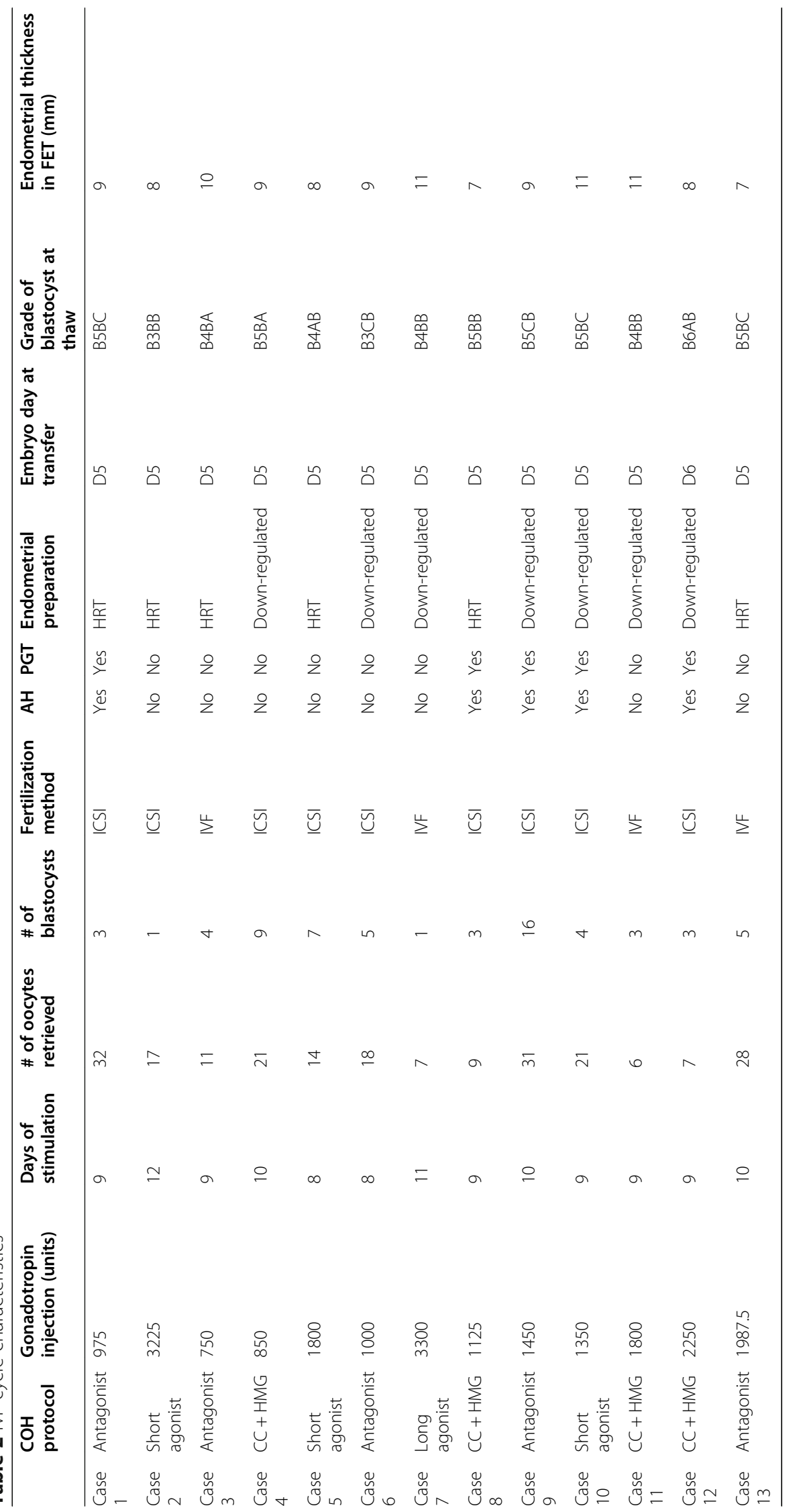




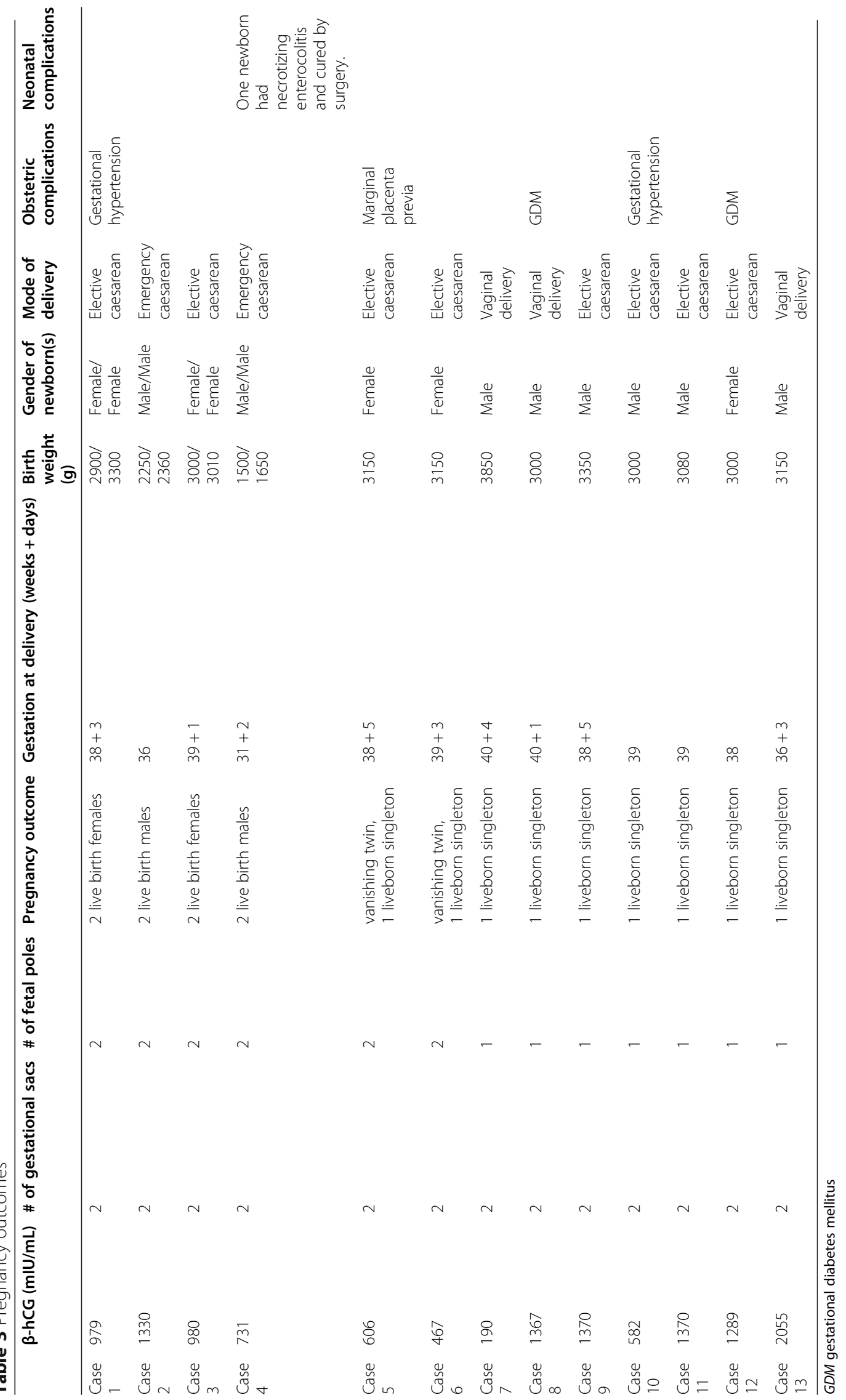


Table 4 Demographic and IVF-FET cycle characteristics in monochorionic and dichorionic twining group

\begin{tabular}{|c|c|c|c|}
\hline & $\begin{array}{l}\text { Monochorionic } \\
(n=29)\end{array}$ & $\begin{array}{l}\text { Dichorionic } \\
(n=14)\end{array}$ & $P$-value \\
\hline Age at IVF (years) & $34.7 \pm 4.5$ & $35.4 \pm 4.7$ & 0.674 \\
\hline Body mass index $\left(\mathrm{kg} / \mathrm{m}^{2}\right)$ & $22.4 \pm 3.8$ & $21.2 \pm 2.4$ & 0.301 \\
\hline Primary infertility & $12(41.4)$ & $5(35.7)$ & 0.722 \\
\hline \multicolumn{4}{|l|}{ Fertilization method } \\
\hline Conventional IVF & $12(41.4)$ & $5(35.7)$ & \multirow[t]{2}{*}{0.722} \\
\hline ICSI & $17(58.6)$ & $9(64.3)$ & \\
\hline \multicolumn{4}{|l|}{ Assisted hatching } \\
\hline No & $16(55.2)$ & $8(57.1)$ & \multirow[t]{2}{*}{0.903} \\
\hline Yes & $13(44.8)$ & $6(42.9)$ & \\
\hline \multicolumn{4}{|l|}{ PGT } \\
\hline No & $17(58.6)$ & $8(57.1)$ & \multirow[t]{2}{*}{0.927} \\
\hline Yes & $12(41.4)$ & $6(42.9)$ & \\
\hline \multicolumn{4}{|l|}{ Embryo day at transfer } \\
\hline Day 5 & $23(79.3)$ & $12(85.7)$ & \multirow[t]{2}{*}{0.613} \\
\hline Day 6 & $6(20.7)$ & $2(14.3)$ & \\
\hline \multicolumn{4}{|l|}{ Endometrial preparation } \\
\hline Natural cycle & $2(6.9)$ & $1(7.1)$ & \multirow[t]{2}{*}{0.976} \\
\hline HRT or down-regulated & $27(93.1)$ & $13(92.9)$ & \\
\hline Endometrial thickness in FET (mm) & $9.0 \pm 1.1$ & $8.9 \pm 1.4$ & 0.856 \\
\hline
\end{tabular}

Data presented as mean \pm SD or $\mathrm{n}(\%)$

monozygotic DC-DA twining is assumed to develop when a cleavage embryo splits within the first 3 days after fertilization, before the inner cell mass cells differentiate [14]. As Herranz writes, the theory was quickly accepted due to Corner's prestige, the internal logic of the model, and the convincing nature of his graphic depiction [15]. The universally accepted idea about the various modes of monozygotic twinning (addressed as 'the mode') is based on few experimental data, because embryo experimentation must meet restrictions in humans [16]. However, our study reported 13 single blastocyst FET cases resulted monozygotic DC-DA twinning, which challenged the golden rule.

In our retrospective study examining a large cohort of single blastocyst FETs, we report a 2.8\% MZT pregnancy rate following single blastocyst FET, comparable to previous studies $[5,6]$. Most of the MZT pregnancies were monochorionic, similar to the previous report [6]. The incidence rate of monozygotic DC-DA pregnancies was $0.5 \%(13 / 2510)$ after single blastocyst FET in our study. Most previous studies of single blastocyst transfer resulted in DC-DA twins are case reports. A recent study reported four cases of single blastocyst transfer resulted in monozygotic DC-DA twins in down-regulated controlled FET cycles, the incidence rate of monozygotic DC-DA pregnancies was $0.3 \%(4 / 1181)$ after single blastocyst FET [17], which was comparable with our study. Other case reports stated atypical hatching would lead to monozygotic twinning after single blastocyst transfer $[2,18,19]$. Another research including 4976 clinical gestations showed that they had never observed an embryo division in half before the blastocyst stage during over 15 years of IVF treatment and laboratory experience [14]. Alone with our findings, the popular credo of chorionicity simply based upon the day of embryonic development must be reevaluated. Moreover, there must be an underestimation of the rate of monozygotic DCDA twins associated with IVF treatment, because monozygotic multiple pregnancies may not be noticed if more than one embryo are transferred. Since all the published studies are retrospective or case reports with small sample sizes and lack of fetal or neonatal genetic analyses, which makes it difficult to draw concrete conclusions against the long believed dogma and needs further research

The mechanism of monozygotic division is still unknown. Micromanipulation of the zona pellucida during ICSI, embryo biopsy, and assisted hatching has been reported to be risk factors associated with monozygotic pregnancy during IVF treatment in a lot of studies [9, 19, 20]. According to the most popular theory, $\mathrm{AH}$ might increase the incidence of the inner cell mass split and two fetal plates consequently develop [19]. While some other studies show opposite results, that embryo 


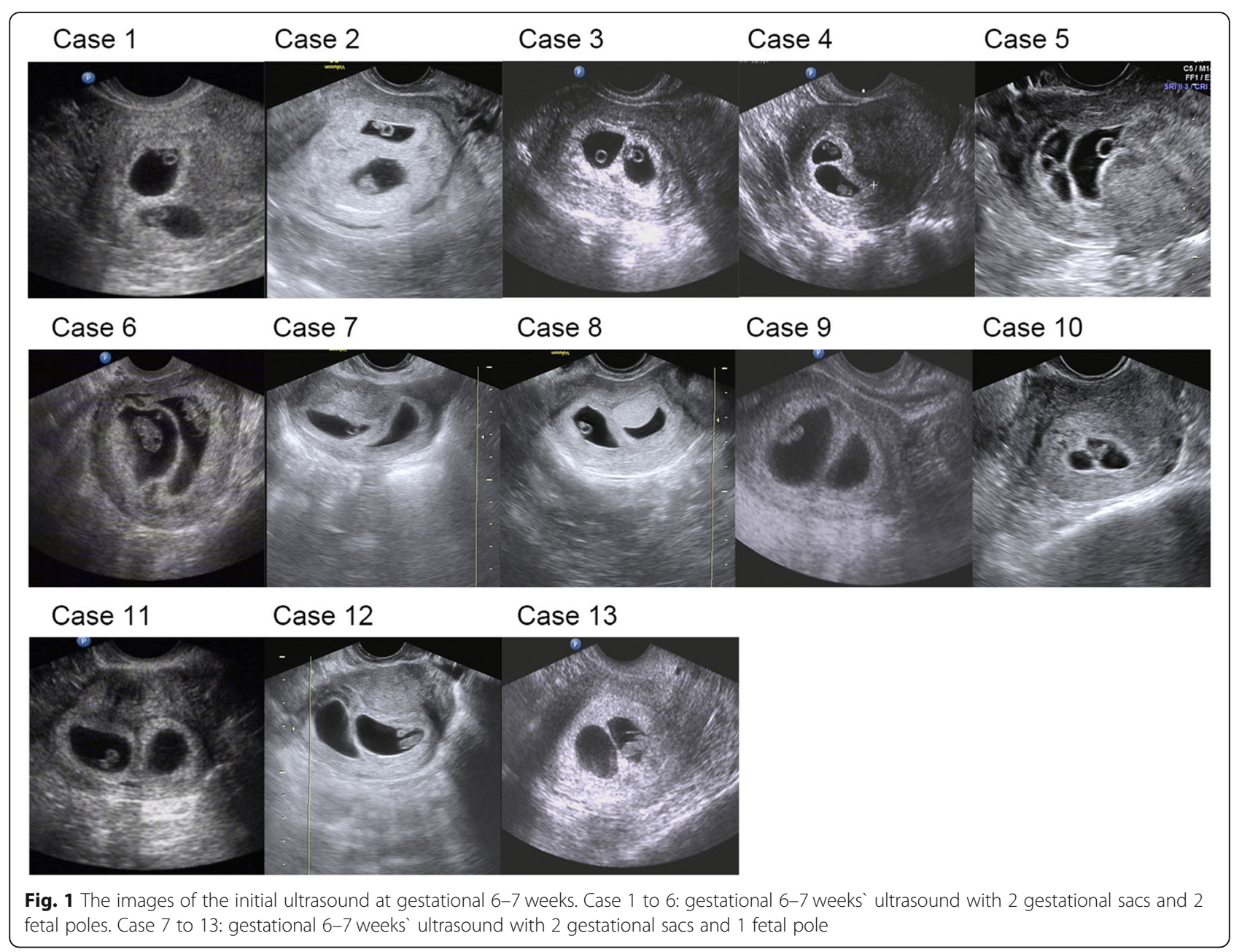

manipulation (ICSI, assisted hatching, embryo biopsy) do not increase the risk of monozygotic pregnancies [9, 21]. In our 13 cases, possible previously reported risk factors related to the incidence of monozygotic multiple pregnancy were embryo biopsy for PGT, AH, ICSI and extended culture. Both $\mathrm{AH}$ and embryo biopsy were performed in 5 of the 13 cases; ICSI was done in 9 of the 13 cases in the study.

Single blastocyst transfer is recommended in many countries as it has a favorable prognosis for live-birth as well as low multiple pregnancy. But extended culture may play a role in the development of MZT. Transferring embryos at blastocyst stage exposes the embryo to extra time in the in-vitro environment and may have some effects on the embryo and therefore increase the chance of embryo division. A retrospective analysis showed a 5.6\% MZT pregnancy rate in the blastocyst transfer group compared with $2 \%$ in the cleavage embryo group [22]. The mechanism is speculated to be long exposure to low levels of calcium might harm the Intracellular stabilization and consequently lead to the division of the inner cell mass $[3,19]$. Our study showed a $2.8 \%$ MZT pregnancy rate following single blastocyst FET, which was lower than the above study. While another study showed no increase in multiple pregnancies relative to the embryo stage in either the DC-DA or MC-DA twinning [23]. Risk factors for embryo division remain controversial and more researches are needed to answer the question.

A strength of our study is that it includes only downregulated and HRT single frozen blastocyst transfer, with ultrasound confirming no ovulation during endometrial preparation in FET cycle to rule out the possibility of dizygotic DC-DA twinning. To the best of our knowledge, this is the largest case series about monozygotic multichorionic twining after single blastocyst transfer. One limitation of our study is that monozygosity was not verified by the genetic analysis of the offspring, which is thought to be the gold standard. Therefore, in the future study, we should pay more attention to confirm monozygosity with genetic analysis which is very important and should not be neglected. Another limitation is that 
we do not routinely take pictures of the transferred embryo on the FET day, so we lack the data of the 13 transferred blastocysts of our included cases.

\section{Conclusion}

In conclusion, we reviewed 13 cases found among 5415 single blastocyst FET cycles resulted in a monozygotic DC-DA gestation. This is the largest case series showed that single blastocyst transfer could result monozygotic DC-DA pregnancies during IVF treatment which challenged the accepted theory. Patients should be informed of a possible increased risk of monozygotic multiple pregnancies after single blastocyst FET. The frequency and mechanism of how the monozygotic multichorionic pregnancy occurs after single blastocyst transfer is still unknown. Further studies are needed to clarify the mechanism of monozygotic splitting, especially the effects of IVF treatment on early embryo development.

\begin{abstract}
Abbreviations
AH: Assisted hatching; ART: Assisted reproductive technology;

CC: Clomiphene citrate; DC-DA: Dichorionic-diamniotic; FET: Frozen embryo transfer; FSH: Follicle-stimulating hormone; GDM: Gestational diabetes mellitus; GnRH: Gonadotropin-releasing hormone; hCG: human chorionic gonadotropin; hMG: human menopausal gonadotropin; HRT: Hormone replacement treatment; ICSI: Intracytoplasmic sperm injection; IVF: In vitro fertilization; MC-DA: Monochorionic-diamniotic; MC-MA: Monochorionicmonoamniotic; MZT: Monozygotic twinning; PCR: Polymerase chain reaction; PCOS: Polycystic ovarian syndrome; PGT: Preimplantation genetic testing; SNM1: Survival motor neuron gene; WGA: Whole genome amplification
\end{abstract}

\section{Acknowledgements}

We would like to thank all the staff in the Shanghai Ji Ai Genetics and IVF Institute, Obstetrics and Gynecology Hospital, Fudan University, for their help.

\section{Authors' contributions}

HL, TS and XS conceived and designed the study. HL and TS drafted and critically revised the manuscript for important intellectual content. HL sought ethical approval. All the authors contributed to the further writing of the manuscript and approved the final manuscript.

\section{Funding}

This study is financially supported by Shanghai Ji Ai Genetics and IVF Institute hospital funding (JA-2019-05), which had no role in the design of the study, the collection, analysis, and interpretation of data and in writing the manuscript.

\section{Availability of data and materials}

The datasets analyzed during the current study are available from the corresponding author on reasonable request.

\section{Ethics approval and consent to participate}

This study was approved by the Ethics Committee of Assisted Reproductive Medicine in Shanghai JiAi Genetics \& IVF Institute (JIAI E2020-02). All patients consented to participate in the research, and oral/written informed consent was obtained from each patient.

\section{Consent for publication}

We have obtained consent to publish from each patient.

\section{Competing interests}

The authors declare that they have no competing interests.

\section{Author details}

'Shanghai Ji Ai Genetics and IVF Institute, Obstetrics and Gynecology Hospital, Fudan University, Shanghai 200011, China. ${ }^{2}$ Key Laboratory of
Female Reproductive Endocrine Related Diseases, Obstetrics and Gynecology Hospital, Fudan University, Shanghai, China.

Received: 19 April 2020 Accepted: 22 November 2020

Published online: 10 December 2020

\section{References}

1. Corner GW. The observed embryology of human single-ovum twins and other multiple births. Am J Obstet Gynecol. 1955;70:933-51.

2. Shibuya $Y$, Kyono K. A successful birth of healthy monozygotic dichorionic diamniotic (DD) twins of the same gender following a single vitrifiedwarmed blastocyst transfer. J Assist Reprod Genet. 2012;29:255-7.

3. Busnelli A, Dallagiovanna C, Reschini M, Paffoni A, Fedele L, Somigliana E. Risk factors for monozygotic twinning after in vitro fertilization: a systematic review and meta-analysis. Fertil Steril. 2019;111:302-17.

4. Hviid KVR, Malchau SS, Pinborg A, Nielsen HS. Determinants of monozygotic twinning in ART: a systematic review and a meta-analysis. Hum Reprod Update. 2018;24:468-83.

5. Kanter JR, Boulet SL, Kawwass JF, Jamieson DJ, Kissin DM. Trends and correlates of monozygotic twinning after single embryo transfer. Obstet Gynecol. 2015;125:111-7.

6. Knopman JM, Krey LC, Oh C, Lee J, McCaffrey C, Noyes N. What makes them split? Identifying risk factors that lead to monozygotic twins after in vitro fertilization. Fertil Steril. 2014;102:82-9.

7. Skiadas CC, Missmer SA, Benson CB, Gee RE, Racowsky C. Risk factors associated with pregnancies containing a monochorionic pair following assisted reproductive technologies. Hum Reprod. 2008;23:1366-71.

8. Tarlatzis BC, Qublan HS, Sanopoulou T, Zepiridis L, Grimbizis G, Bontis J. Increase in the monozygotic twinning rate after intracytoplasmic sperm injection and blastocyst stage embryo transfer [3]. Fertil Steril. 2002;77:1968.

9. Mateizel I, Santos-Ribeiro S, Done E, Van Landuyt L, Van De Velde H, Tournaye $\mathrm{H}$, et al. Do ARTs affect the incidence of monozygotic twinning? Hum Reprod. 2016;31:2435-41.

10. Tocino A, Blasco V, Prados N, Vargas MJ, Requena A, Pellicer A, et al. Monozygotic twinning after assisted reproductive technologies: a case report of asymmetric development and incidence during 19 years in an international group of in vitro fertilization clinics. Fertil Steril. 2015;103:11859.

11. Gardner DK, Lane M, Stevens J, Schlenker T, Schoolcraft WB. Blastocyst score affects implantation and pregnancy outcome: towards a single blastocyst transfer. Fertil Steril. 2000;73:1155-8.

12. Yovich JL, Stanger JD, Grauaug A, Barter RA, Lunay G, Dawkins RL, et al. Monozygotic twins from in vitro fertilization. Fertil Steril. 1984;41:833-7.

13. Schlueter R, Arnett C, Huang C, Burlingame J. Successful quintuplet pregnancy of monochorionic male quadruplets and single female after double embryo transfer: case report and review of the literature. Fertil Steril. 2018;109:284-8.

14. Knopman J, Krey LC, Lee J, Fino ME, Novetsky APP, Noyes N. Monozygotic twinning: an eight-year experience at a large IVF center. Fertil Steril. 2010;94: 502-10

15. Herranz G. The timing of monozygotic twinning: a criticism of the common model. Zygote. 2015;23(1):27-40.

16. Denker HW. Comment on G. Herranz: the timing of monozygotic twinning: a criticism of the common model. Zygote. 2015;23(2):312-4.

17. Sundaram V, Ribeiro S, Noel M. Multi-chorionic pregnancies following single embryo transfer at the blastocyst stage: a case series and review of the literature. J Assist Reprod Genet. 2018;35:2109-17.

18. Van Langendonckt A, Wyns C, Godin PA, Toussaint-Demylle D, Donnez J. Atypical hatching of a human blastocyst leading to monozygotic twinning: a case report. Fertil Steril. 2000;74:1047-50.

19. Yamashita S, Ikemoto Y, Ochiai A, Yamada S, Kato K, Ohno M, et al. Analysis of 122 triplet and one quadruplet pregnancies after single embryo transfer in Japan. Reprod BioMed Online. 2020;40:374-80.

20. Ikemoto $Y$, Kuroda K, Ochiai A, Yamashita S, Ikuma S, Nojiri S, et al. Prevalence and risk factors of zygotic splitting after 937848 single embryo transfer cycles. Hum Reprod. 2018;33:1984-91.

21. Vega M, Zaghi S, Buyuk E, Jindal S. Not all twins are monozygotic after elective single embryo transfer: analysis of 32,600 elective single embryo transfer cycles as reported to the Society for Assisted Reproductive Technology. Fertil Steril. 2018;109:118-22. 
22. Milki AA, Jun SH, Hinckley MD, Behr B, Giudice LC, Westphal LM. Incidence of monozygotic twinning with blastocyst transfer compared to cleavagestage transfer. Fertil Steril. 2003;79:503-6.

23. Osianlis T, Rombauts L, Gabbe M, Motteram C, Vollenhoven B. Incidence and zygosity of twin births following transfers using a single fresh or frozen embryo. Hum Reprod. 2014;29:1438-43.

\section{Publisher's Note}

Springer Nature remains neutral with regard to jurisdictional claims in published maps and institutional affiliations.

Ready to submit your research? Choose BMC and benefit from:

- fast, convenient online submission

- thorough peer review by experienced researchers in your field

- rapid publication on acceptance

- support for research data, including large and complex data types

- gold Open Access which fosters wider collaboration and increased citations

- maximum visibility for your research: over $100 \mathrm{M}$ website views per year

At BMC, research is always in progress.

Learn more biomedcentral.com/submissions 